\title{
Valores de la relación grasa/proteína y nitrógeno ureico en leche de vacas lecheras de la zona norte de Alajuela y Heredia, Costa Rica
}

\section{Values for protein/fat ratio and milk urea nitrogen in milk from dairy cows in northern Alajuela and Heredia, Costa Rica}

\section{Diana Vargas Sobrado ${ }^{1}$, Jaime Murillo Herrera² ${ }^{2}$ Frank Hueckmann Voss ${ }^{3}$,

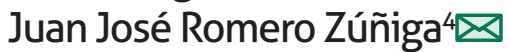

1 Consultora independiente. E-mail: diana08ben@yahoo.com

2 Consultor independiente. E-mail: jmurillo80@gmail.com

3 Consultor independiente. E-mail: huecsedo@hotmail.com

4 Programa de Investigación en Medicina Poblacional, Escuela de Medicina Veterinaria, Universidad Nacional. E-mail: juan.romero.zuniga@una.cr

Recibido: 06 de Julio de 2016. Corregido: 27 de Setiembre de 2016. Aceptado: 15 de Octubre de 2016.

Resumen: Los componentes de la leche brindan una herramienta económica, menos invasiva al monitorear el balance metabólico y la ración suministrada a ganado lechero. Con el fin de determinar valores de grasa, proteína, la relación grasa/proteína y nitrógeno ureico, en vacas lecheras de Costa Rica, se tomó muestras de leche de 442 animales, durante los dos ordeños del día, en abril y agosto del 2012, en cuatro fincas productoras de leche de la zona norte de Alajuela y Heredia. Cada uno de estos componentes se analizó, mediante estadística descriptiva y comparaciones de promedios, en diferentes categorías, según cantidad de días en lactación, número de lactancias, mes de muestreo y raza. Se obtuvo niveles promedio de proteína de 3,34\% (IC 95\%: 3,29-3,37), grasa 4,13\% (IC 95\%: 4,04-4,22), nitrógeno ureico 16,81 mg/dl (IC 95\%: 16,64-17,26), y una relación grasa/proteína promedio de 1,26 (IC 95\%: 1,24-1,28). Hubo diferencias en los componentes según raza, número de lactancias y días en lactación. Las variaciones existentes, en los porcentajes de grasa, proteína, relación grasa/proteína y nitrógeno ureico, según la etapa productiva del animal, la raza, la época de muestreo y días en lactancia, podrían indicar desbalances metabólicos; por tanto, debe tomarse en cuenta a la hora de analizar el desempeño productivo y reproductivo así como la dieta de las vacas.

Palabras claves: enfermedades metabólicas, acidosis ruminal, cetosis, pastoreo, lechería, salud de hato, producción, reproduction.

\begin{abstract}
Milk components provide an economical and less invasive tool to monitor metabolic balance and food rations given to dairy cattle. In order to determine values for fat, protein, protein/fat ratio, and milk urea nitrogen in Costa Rican dairy cows, milk samples were taken from 442 animals from four specialized dairy farms in northern Alajuela and Heredia, during the two daily milkings in April and August 2012. Each component was analyzed using descriptive statistics and comparing means for different categories according to days in lactation, parity number, season of sampling and breed. Average levels were found at $3.34 \%$ for protein $(95 \%$
\end{abstract}


$\mathrm{Cl}$ : 3.29-3.37), 4.13\% for fat (95\% Cl: 4.04-4.22), and $16.81 \mathrm{mg} / \mathrm{dl}$ for urea nitrogen (95\% Cl: 16.64-17.26), as well as an average protein/fat ratio of 1.26 (95\% Cl: 1.24-1.28). There were differences in the components based on breed, parity number and days in lactation. Variations in the percentages of fat, protein, protein/fat ratio and milk urea nitrogen according to breed, parity number, season and days in lactation may indicate metabolic imbalances; consequently, the foregoing must be taken into account when analyzing the diet of cows and their productive and reproductive performance.

Keywords: metabolic diseases, ruminal acidosis, ketosis, grazing, dairy farm, herd health, production, reproduction.

\section{Introducción}

El objetivo fundamental en un programa de salud de hato, con animales de producción, consiste en mantener su salud y la producción en el nivel más eficiente; que provea un retorno económico competitivo para el productor, así como introducir técnicas que continúen mejorando la eficiencia (Brand et al. 1996; Radostitis 2001). Con este fin, se ha desarrollado protocolos estrictos de control y prevención de enfermedades, basados en una vigilancia continua y monitoreo del hato (Van Ranst et al. 2008). El objetivo del monitoreo es obtener señales tempranas de actuales o potenciales desviaciones del rendimiento en áreas como: producción, fertilidad y salud de la ubre. Estas señales pueden guiar a análisis más específicos del problema y su solución (Noordhuizen 2002). El estado de evolución incesante provoca que los lecheros estén, constantemente, enfrentando un nuevo nivel de producción (Niles 2010).

Las enfermedades metabólicas y nutricionales aumentan conforme se incrementa la producción de leche y el número de lactancias (Oetzel 2007). Como resultado de esto, siempre se debe trabajar en herramientas de evaluación de desempeño, las cuales son necesarias para identificar los obstáculos que previenen el progreso en el hato, así como el nivel de producción actual (Niles 2010).

Analizar los componentes de la leche permite estimar problemas mayores en la nutrición del hato; predecir y prevenir posibles disturbios metabólicos y reproductivos (Kuterovac et al. 2005); además, monitorear la incidencia de enfermedades metabólicas; también, como una ventana para analizar el programa de alimentación (Radostitis 2001).

La producción de grasa y proteína varía en gran manera de un hato a otro, debido a varios factores, los cuales se pueden manipular para alcanzar valores incluso por arriba del promedio. Entre estos se puede citar la etapa de lactancia, la edad del animal, época del año, estado de salud del animal, problemas de mastitis, genética, nutrición y prácticas de alimentación (Heinrichs et al. 2005).

Por otra parte, al contar con los valores de grasa y proteína de la leche, es importante analizar la relación grasa/proteína, con el fin de evaluar la nutrición, la conversión de nutrientes y el metabolismo de cada animal (Toni et al. 2011). 
Asimismo, el análisis individual del nitrógeno ureico en leche (MUN por sus siglas en inglés) ha ganado terreno en América del Norte durante la última década, dado que provee información actualizada del estado nutricional de los animales (Arunvipas et al. 2004) y se ha considerado un indicador de la eficiencia al utilizar el nitrógeno por parte de las vacas lecheras (Cao et al. 2010). Se parte de la evidencia de que las concentraciones en leche son similares a las de sangre; siendo más fácil obtener las muestras rutinarias de leche, lo cual permite un mejor asesoramiento por mediciones regulares del MUN (González \& Vásquez 2000). Su análisis en leche se puede usar como indicador de problemas potenciales en la alimentación de las vacas y, al compararlo con los contenidos de grasa y proteína en un momento dado, se puede identificar problemas nutricionales (González \& Vásquez 2000); lo cual, permite reforzar la ración (Hwang et al. 2000); al igual que evaluar la presencia de enfermedad en forma clínica o subclínica y determinar trastornos de producción, dado que determinan el rendimiento del hato (Padilla 2010).

Con el objetivo de que la información generada permita, de manera objetiva y mediante un método económico y menos invasivo, evaluar el desempeño productivo y la salud de las vacas lecheras de esta zona, que representa una extensa zona de vida en la cual se produce leche en Costa Rica, este trabajo determina los valores de grasa, proteína y la relación grasa/proteína, así como el MUN, para las razas Holstein y Jersey, según días en lactación y número de lactancia, para sistemas en pastoreo del área norte de Alajuela y Heredia.

\section{Materiales y métodos}

\section{Tipo de estudio y población blanco}

El estudio es de tipo transversal, descriptivo, con dos muestreos independientes, el primero entre marzo y mayo; el segundo en agosto del 2012. Se distribuyó el muestreo en dos períodos por razones del costo económico del procesamiento de las muestras.

Se tomó como población blanco las fincas de la zona norte de Alajuela y Heredia, dada su alta representatividad de fincas que se ubican en esa zona de vida (Bosque húmedo montano-Bajo); a una altitud entre 1500 y 2300 msnm, con una precipitación anual media entre 1000 y $2000 \mathrm{~mm}$ y un rango de temperatura anual media de $12-17^{\circ} \mathrm{C}$.

Se trabajó en cuatro fincas de lechería especializada, cuyos propietarios estuvieron anuentes a colaborar con el estudio y a cubrir parte de los costos de las determinaciones de los componentes de la leche. En las cuatro fincas se ordeña, con sistemas mecánicos, los animales dos veces al día, con una diferencia de entre 10 y 12 horas entre ordeños. Utilizan pastos de piso como kikuyu (Penisetum clandestinum) y ryegrass (Lolium multiflorum), suplementación con alimentos concentrados y sales minerales; además, tienen visita periódica de médico veterinario para su programa de Salud de Hato, y poseen el sistema de información VAMPP Bovino 3.0 (Noordhuizen \& Buurman 1984; Romero et al. 2000). En dos fincas se posee la raza Jersey y Holstein en forma pura, así como sus cruces; mientras que, en las otras dos tienen solo una raza, en forma pura, sea Jersey o Holstein. El número de animales en ordeño, por finca, fue de $68,86,105$ y 253 , respectivamente. 
Se utilizó animales en período de lactancia, desde la primer semana hasta el final de la lactación; otros animales, desde su primer lactancia hasta la décima. El total de animales evaluados fue de 442.

\section{Método de toma de muestras de leche}

Las muestras se tomaron en forma individual, en ambos ordeños (am y pm), posterior a la limpieza de la ubre y el despunte de cada pezón. Cada muestra se depositó en bolsas suministradas por el laboratorio de calidad de leche de la Cooperativa de Productores de Leche Dos Pinos R.L. (Dos Pinos). Se tomó dos muestras por animal, una para el conteo de células somáticas y componentes (sólidos totales, grasa, proteína), y otra para la determinación del nitrógeno ureico en leche.

Para garantizar la homogeneidad de la muestra, se tomó directamente de la pesa o del tanque individual, pues ofrece menor error en los resultados (Oetzel 2007). Para efectos de este estudio, por razón de presupuesto, el MUN se determinó únicamente en el muestreo de la mañana.

Las muestras se mantuvieron en una hielera, a $4^{\circ}$ Celsius, y fueron llevadas al laboratorio de calidad de leche de la Cooperativa Dos Pinos el mismo día. La entrega de los resultados se dio en un promedio de ocho días.

\section{Determinación de los componentes de la leche}

Los sólidos totales fueron determinados con el equipo Milko Scan ${ }^{T M}$ FT-120. Por su parte, las determinaciones de MUN se hicieron mediante el método enzimático y la cuantificación por espectrofotometría, usando el equipo ChemSpec®150. Mientras, el conteo de células somáticas se realizó con el Fossomatic 420®.

\section{Registro de la información de los animales}

Los datos de los animales estaban sistematizados en el programa informático VAMPP Bovino 3.0 (Romero et al. 2000). Mediante este sistema se obtuvo los datos de la raza, número de partos (lactancias) y días en lactancia.

\section{Análisis de los datos}

Se realizó estadística descriptiva, en la cual se calculó medidas de tendencia central (media y mediana) y medidas de dispersión (mínimo, máximo y desviación estándar) para las variables en forma continua $y$, para las variables en forma discreta, se calcularon porcentajes con sus respectivos intervalos de confianza al $95 \%$. Asimismo, se realizaron pruebas de hipótesis de diferencias de promedios entre las categorías de las variables. 


\section{Resultados y Discusión}

\section{Características de los animales}

Las características generales de los 442 animales muestreados para este estudio, tales como la cantidad de lactancias, días en lactación y porcentajes de grasa, proteína y nitrógeno ureico, así como los niveles de producción láctea según el número de lactancias, los días en lactancia y la raza, se presentan en el Cuadro 1.

Cuadro 1. Estadística descriptiva para número de muestra, cantidad de lactancias, días en lactación, días en producción y componentes de la leche en vacas Holstein y Jersey de cuatro hatos lecheros especializados de Costa Rica.

\begin{tabular}{|c|c|c|c|c|c|}
\hline & $\mathbf{n}$ & Promedio & D.E & Mín. & Máx. \\
\hline Lactancias & 442 & 2,73 & 1,60 & 1,00 & 10,00 \\
\hline Días en lactación & 442 & 167,42 & 104,28 & 2,00 & 500,00 \\
\hline Grasa (\%) & 442 & 4,13 & 0,90 & 1,50 & 6,80 \\
\hline Jersey & 290 & 4,48 & 0,80 & 2,80 & 6,80 \\
\hline Holstein & 152 & 3,45 & 0,65 & 1,50 & 5,30 \\
\hline Proteína (\%) & 442 & 3,34 & 0,38 & 2,35 & 5,23 \\
\hline Jersey & 290 & 3,45 & 0,32 & 2,77 & 4,60 \\
\hline Holstein & 152 & 3,13 & 0,40 & 2,35 & 5,23 \\
\hline MUN (mg dL) & 434 & 16,80 & 3,00 & 8,50 & 24,70 \\
\hline Jersey & 289 & 16,96 & 3,02 & 8,90 & 24,70 \\
\hline Holstein & 145 & 16,52 & 3,05 & 8,50 & 23,70 \\
\hline Producción leche $(\mathrm{Kg} / \mathrm{d})$ & 442 & 24,74 & 7,99 & 2,50 & 50,00 \\
\hline \multicolumn{6}{|l|}{ Raza } \\
\hline Jersey & 290 & 24,12 & 7,13 & 9,50 & 45,00 \\
\hline Holstein & 152 & 25,92 & 9,34 & 2,50 & 50,00 \\
\hline \multicolumn{6}{|l|}{ Número lactancia } \\
\hline $1-2$ & 228 & $21,86^{a}$ & 6,07 & 9,50 & 39,00 \\
\hline $3-4$ & 149 & $28,78^{b}$ & 7,95 & 9,00 & 50,00 \\
\hline$\geq 5$ & 65 & 26,06 & 9,20 & 8,50 & 46,00 \\
\hline \multicolumn{6}{|l|}{ Días de lactancia } \\
\hline $1-60$ & 64 & $28,38^{a}$ & 6,74 & 15,00 & 45,00 \\
\hline $61-120$ & 65 & $27,86^{\mathrm{a}}$ & 7,48 & 9,50 & 44,00 \\
\hline $121-200$ & 154 & $26,66^{a}$ & 7,27 & 10,00 & 50,00 \\
\hline$>200$ & 159 & $20,34^{b}$ & 7,08 & 8,50 & 40,50 \\
\hline
\end{tabular}


Porcentaje de grasa en leche

Las vacas Jersey produjeron el mayor porcentaje de proteína en leche que las Holstein $(\mathrm{P}<$ $0,0001)$. En cuanto al número de lactancias por animal, aunque se observó un incremento en el porcentaje de grasa conforme se incrementa el número de partos, este no fue estadísticamente significativo $(P=0,24)$. Por su parte, la proteína muestra un efecto general de incremento a medida que transcurre la lactación ( $P<0,0001)$ (Figura 1); sin embargo, muestra una leve reducción entre los 60 y 120 días de lactación $(P=0,03)$. Asimismo, hubo un mayor porcentaje promedio de proteína en la época lluviosa que en la seca (Cuadro 2).

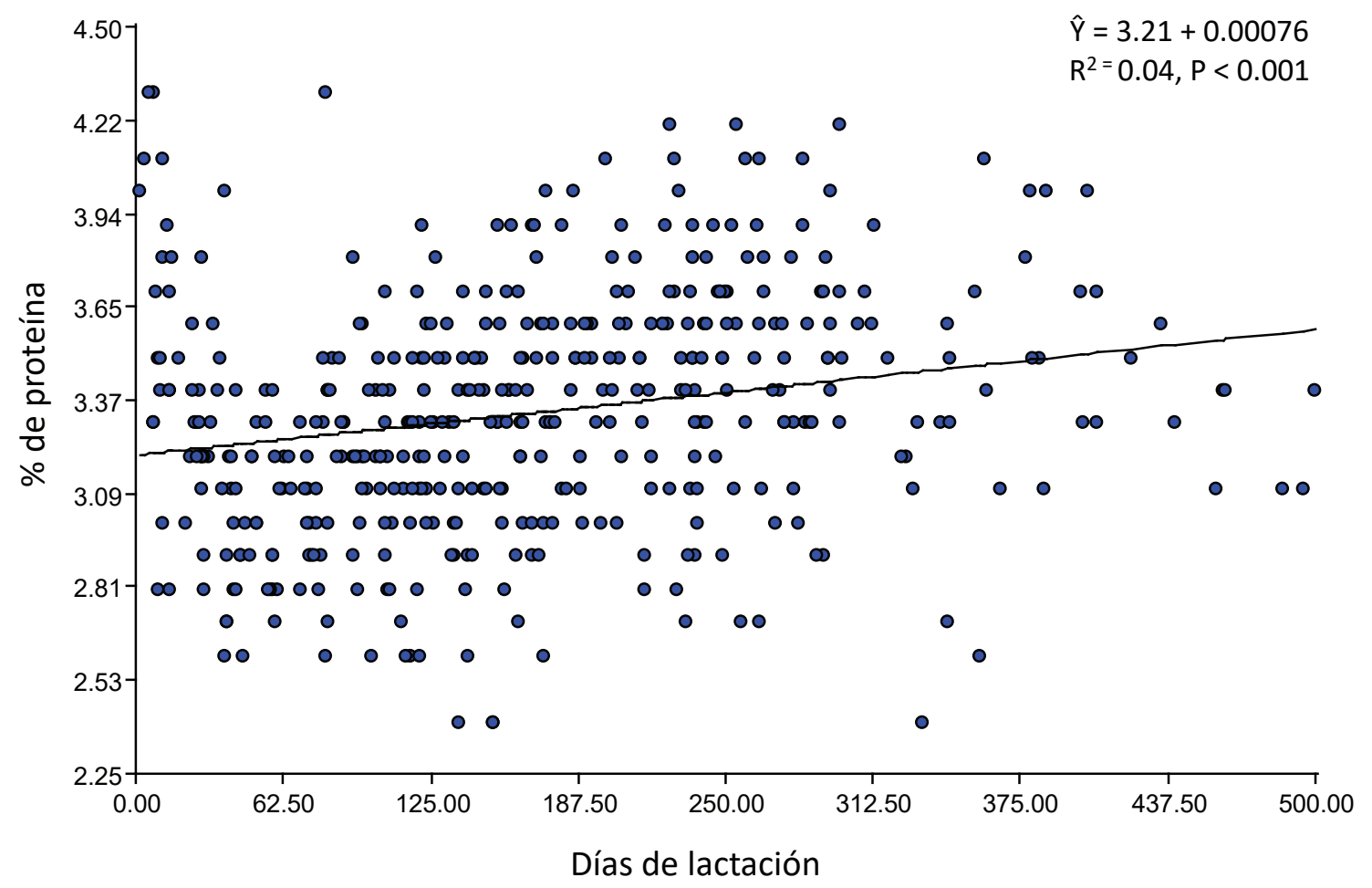

Figura 1. Relación entre el porcentaje de proteína láctea y días de lactación en vacas Holstein y Jersey de cuatro hatos lecheros especializados de Costa Rica.

Porcentaje de grasa en leche

El porcentaje de grasa fue significativamente mayor en el ordeño de la tarde, respecto al de la mañana $(P=0,003)$; no mostró cambios significativos durante el desarrollo de la lactación, mostrando su máximo (4,32\%) sobre los 200 días; su mínimo entre los 60 y 120 
días $(4,09 \%)$. Conforme aumentaron las lactancias disminuyó el porcentaje de grasa en leche, observándose el menor nivel $(4,08 \%)$ en las de cinco lactancias o más ( $P=0,03)$. En cuanto a la raza, los animales Jersey produjeron, en promedio, poco más de un $1 \%$ absoluto de grasa que las Holstein $(P<0,001)$. Se observa porcentajes superiores de grasa durante la época de lluvias (Cuadro 3).

Cuadro 2. Promedios de proteína en leche según hora de ordeño, número de lactancia, días en lactación, raza y época de año, en vacas Holstein y Jersey de cuatro hatos lecheros especializados de Costa Rica.

\begin{tabular}{|c|c|c|c|c|c|c|}
\hline Variable & Estrato & $\mathbf{n}$ & Media & DE & Mín. & Мáx. \\
\hline Promedio general & & 442 & 3,34 & 0,38 & 2,35 & 5,23 \\
\hline \multirow[t]{2}{*}{ Hora ordeño } & am & 442 & 3,33 & 0,38 & 2,33 & 5,73 \\
\hline & $\mathrm{pm}$ & 442 & 3,34 & 0,38 & 2,35 & 5,23 \\
\hline \multirow[t]{3}{*}{ Número lactancia } & $1-2$ & 228 & 3,32 & 0,34 & 2,58 & 4,44 \\
\hline & $3-4$ & 149 & 3,35 & 0,42 & 2,41 & 4,60 \\
\hline & $\geq 5$ & 65 & 3,36 & 0,42 & 2,35 & 5,23 \\
\hline \multirow[t]{4}{*}{ Días de lactancia } & $1-60$ & 64 & $3,34^{\mathrm{a}}$ & 0,49 & 2,54 & 5,23 \\
\hline & $61-120$ & 65 & $3,17^{\mathrm{b}}$ & 0,30 & 2,60 & 4,24 \\
\hline & $121-200$ & 154 & $3,29^{a}$ & 0,35 & 2,35 & 4,09 \\
\hline & $>200$ & 159 & $3,47^{\mathrm{a}}$ & 0,36 & 2,41 & 4,44 \\
\hline \multirow[t]{2}{*}{ Raza } & Hosltein & 152 & $3,13^{a}$ & 0,40 & 2,35 & 5,23 \\
\hline & Jersey & 290 & $3,45^{\mathrm{b}}$ & 0,32 & 2,77 & 4,60 \\
\hline \multirow[t]{2}{*}{ Época muestreo } & Seca & 256 & $3,24^{\mathrm{a}}$ & 0,40 & 2,25 & 5,23 \\
\hline & Lluviosa & 286 & $3,46^{b}$ & 0,31 & 2,77 & 4,60 \\
\hline
\end{tabular}

Literales distintos representan diferencias significativas entre estratos de la variable con un valor umbral $\alpha=0,05$. Sólo se muestran las comparaciones que indicaron diferencias. 
Cuadro 3. Promedios de grasa en leche según hora de ordeño, número de lactancia, días en lactación, raza y época de año en vacas Holstein y Jersey de cuatro hatos lecheros especializados de Costa Rica.

\begin{tabular}{|c|c|c|c|c|c|c|}
\hline Variable & Estrato & $\mathbf{n}$ & Media & $\mathrm{DE}$ & Mín. & Máx. \\
\hline Promedio general & & 442 & 4,13 & 0,90 & 1,50 & 4,80 \\
\hline \multirow[t]{2}{*}{ Hora ordeño } & am & 442 & $3,89^{a}$ & 0,99 & 1,30 & 4,54 \\
\hline & $\mathrm{pm}$ & 442 & $4,63^{b}$ & 0,99 & 1,70 & 4,80 \\
\hline \multirow[t]{3}{*}{ Número de lactancia } & $1-2$ & 228 & $4,32^{a}$ & 0,83 & 2,40 & 4,40 \\
\hline & $3-4$ & 149 & $4,24^{a}$ & 1,00 & 1,55 & 4,80 \\
\hline & $\geq 5$ & 65 & $4,08^{b}$ & 0,84 & 2,50 & 4,20 \\
\hline \multirow[t]{4}{*}{ Días en lactación } & $1-60$ & 64 & 4,27 & 0,92 & 2,40 & 4,10 \\
\hline & $61-120$ & 65 & 4,09 & 0,76 & 2,30 & 4,60 \\
\hline & $121-200$ & 154 & 4,16 & 0,93 & 1,50 & 4,70 \\
\hline & $>200$ & 159 & 4,32 & 0,90 & 2,50 & 4,80 \\
\hline \multirow[t]{2}{*}{ Raza } & Holstein & 152 & $3,45^{a}$ & 0,65 & 1,50 & 4,30 \\
\hline & Jersey & 290 & $4,48^{b}$ & 0,80 & 2,80 & 4,80 \\
\hline \multirow[t]{2}{*}{ Época muestreo } & Seca & 256 & $3,79^{a}$ & 0,80 & 1,50 & 4,40 \\
\hline & Lluviosa & 186 & $4,59^{b}$ & 0,80 & 2,80 & 4,80 \\
\hline
\end{tabular}

Literales distintos representan diferencias significativas entre estratos de la variable con un valor umbral $\alpha=0,05$. Sólo se muestran las comparaciones que indicaron diferencias.

\section{Relación grasa/proteína en leche}

En las lecherías evaluadas en este estudio, se observó valores promedios de grasa/proteína menores a 1,5; sin embargo, hubo valores mínimos individuales de hasta 0,78, y máximo de 1,60 (Cuadro 4).

Cuadro 4. Promedio de la relación grasa/proteína en leche de las 4 fincas especializadas, con vacas Holstein y Jersey.

\begin{tabular}{cccccc}
\hline Finca & $\mathbf{n}$ & Media & DE & Mín. & Máx. \\
\hline 1 & 68 & $1,28^{\mathrm{a}}$ & 0,17 & 0,94 & 1,53 \\
2 & 186 & $1,38^{\mathrm{b}}$ & 0,18 & 0,90 & 1,60 \\
3 & 102 & $1,17^{\mathrm{c}}$ & 0,19 & 0,78 & 1,62 \\
4 & 86 & $1,14^{\mathrm{c}}$ & 0,17 & 0,88 & 1,55 \\
\hline
\end{tabular}

Literales distintos representan diferencias significativas entre estratos de la variable con un valor umbral $=0,05$. Sólo se muestran las comparaciones que indicaron diferencias. 
Del total de animales muestreados $(n=442), 33(7,4 \%)$ presentaron valores por debajo de 1,0 (media= 0,89; $\mathrm{DE}=0,12)$; mientras que $368(83,2 \%$ ) están dentro de los valores de 1,0 y 1,5 , considerados normales (media $=1,26 ; \mathrm{DE}=0,14)$. Finalmente, $41(9,27 \%)$ sobrepasó el nivel de 1,5 (media= 1,65; DE=0,10).

\section{Nitrógeno ureico (MUN)}

Este estudio también se propone mostrar, así como se hizo con los valores de grasa y proteína, de qué forma varía el nitrógeno ureico (MUN) según la producción. En el Cuadro 5 , se muestra cómo varía el MUN según número de lactancias, días en lactación, época de muestreo y raza, entre otros factores de manejo no nutricionales.

La media de MUN, encontrada en los 442 animales de este estudio, fue de 16,81 mg/dl (Cuadro 5).

Cuadro 5. Nivel promedio de MUN (mg/dl) en leche según número de lactancia, días en lactación, raza y época de año, de los animales seleccionados para el estudio.

\begin{tabular}{lcccccc}
\hline Variable & Estrato & $\mathbf{n}$ & Media & DE & Mín. & Máx. \\
\hline Promedio general & & 442 & 16,95 & 3.32 & 1.70 & 27.0 \\
Número de lactancia & $1-2$ & 228 & 16,69 & 3.38 & 2.60 & 27.00 \\
& $3-4$ & 149 & 16,96 & 3.32 & 1.70 & 23.80 \\
& $\geq 5$ & 65 & 17,22 & 3.32 & 11.20 & 23.80 \\
Días en lactación & $1-60$ & 64 & $16,76^{\mathrm{a}}$ & 2.64 & 10.90 & 21.20 \\
& $61-120$ & 65 & $17,86^{\mathrm{b}}$ & 3.22 & 10.20 & 23.80 \\
& $121-200$ & 154 & $17,30^{\mathrm{ab}}$ & 3.12 & 8.90 & 23.70 \\
& $>200$ & 159 & $16,32^{\mathrm{a}}$ & 3.68 & 1.70 & 27.00 \\
Raza & & & & & & \\
& Holstein & 152 & 17,03 & 3.29 & 8.50 & 27.00 \\
& Jersey & 290 & 17,32 & 3.41 & 1.70 & 24.70 \\
Época muestreo & Seca & 256 & $16,57^{\mathrm{a}}$ & 3.21 & 2.60 & 27.00 \\
& Lluviosa & 186 & $17,47^{\mathrm{b}}$ & 3.41 & 1.70 & 23.80 \\
\hline
\end{tabular}

Literales distintos representan diferencias significativas entre estratos de la variable con un valor umbral $\alpha=0,05$. Sólo se muestran las comparaciones que indicaron diferencias.

\section{Discusión}

Analizar los componentes de la leche resulta sencillo $y$, de una manera alternativa, permite evaluar la nutrición y la detección rápida de desbalances en la dieta y desórdenes metabólicos subclínicos (Jonker \& Kohn 2001; Eicher 2004). 
A lo largo de la lactancia, la producción de leche sigue una curva de producción bien definida. La grasa y la proteína también siguen una curva, en este caso inversa a la de lactación, debido, principalmente, a un efecto de dilución. La nutrición, y todo lo que influye en la dieta, puede alterar la concentración de grasa y proteína en esta; así, los nutricionistas y veterinarios deben contemplar variables como: una herramienta de monitoreo de la nutrición, eso sí, contemplando factores como raza, edad, época del año y nivel de producción (Eicher 2004).

Los valores de grasa y proteína, según raza, están entre los valores normales esperados para un hato lechero. Esto indica que los animales, con los cuales se trabajó, son especializados en producción de leche, similar a lo reportado por Robinson (2000) y Oetzel (2007), que mencionan, para Holstein, promedios de proteína que van desde $3,15 \%$ hasta $3,25 \%$ y de grasa de $3,4 \%$ a $4,0 \%$; y valores de proteína entre $3,80 \%$ y $3,90 \%$ para la raza Jersey. Hwang et al. (2000). Mencionan valores referenciales de proteína del 3,0\%, e indican que valores inferiores representan un inadecuado consumo de energía en la dieta. A pesar de que los animales utilizados en este estudio no alcanzaron valores tan altos, como los mencionados por Robinson (2000), sí se observa una diferencia significativa $(P=0,0001)$, en la cual la raza Jersey (promedio 3,45\%, DE: 0,32 ) supera los valores de proteína en leche comparada con la Holstein (promedio 3,13, DE: 0,40).

Según Heinrichs (2005), el porcentaje de proteína incrementa, entre 0,02\% y 0,05\%, conforme aumentan las lactancias y la edad del animal. Este mismo patrón se pudo observar en este estudio.

Hatos lecheros, en algunas partes del mundo, muestran patrones estacionales a la hora de evaluar el porcentaje de proteína en la leche (Robinson 2000). En nuestro estudio, se observa que hubo mayor porcentaje de proteína en la época lluviosa que en la seca $(P<0,001)$.

Por otra parte, el porcentaje de grasa, en el nuestro, presentó valores superiores durante la época lluviosa. Esto es producto de la falta de una sustancia capaz de controlar el pH ruminal causado por estrés calórico, aumento en la tasa respiratoria, alcalosis respiratoria y baja en la concentración de bicarbonato sanguíneo. Asimismo, hay otras causas como patrones atípicos de alimentación debido al calor y bajas de fibra en la dieta. Lo anterior lleva a un aumento en el riesgo de acidosis en los animales durante el verano (Oetzel 2007).

La raza determina, también, los valores de grasa en leche, el porcentaje normal de grasa para un hato Holstein debe estar entre 3,4\% y 4,0 \%, mientras que hatos Jersey presentan valores normales entre $4,2 \%$ y $5,0 \%$ de grasa en leche (Oetzel 2007). En este estudio, la producción de grasa en la raza Jersey fue muy superior a la Holstein, como era de esperar, mostrando valores de $4,48 \%(D E: 0,80)$ y $3,45 \%(D E: 0,65)$ respectivamente.

La etapa de lactación influye, sobre la producción de grasa, de forma muy similar a la proteína. Los niveles más altos se observan posterior al parto. Debido al calostro descienden a su punto más bajo entre los 25 y 50 días posparto y ascienden al pico a los 250 días conforme la producción comienza a disminuir (Heinrichs et al. 2005). Esta misma relación se puede observar con los animales muestreados para este estudio, lo cual sugiere una producción normal de grasa a lo largo de la lactancia. 
El número de lactancias y la edad del animal causan una disminución de los valores de grasa conforme envejece (Heinrichs y colaboradores (2005), como resultado de un aumento en la producción y una mayor posibilidad de infecciones de ubre. Este patrón se observa al evaluar el primer grupo de lactancia con el último de este estudio.

Animales post parto tienden a sufrir desbalances energéticosy, debido a que la concentración de grasa tiende a aumentar y la de proteína a disminuir durante este desbalance energético, la medición de la relación grasa/proteína posparto ha sido propuesta como indicador potencial de una falta de energía en la dieta y podría señalar un problema de manejo del período de transición que debe ser tratado a nivel de hato o de grupo de vacas secas y en transición (Toni et al. 2011).

Heuer et al. (1999) reportaron que el límite superior para la relación grasa proteína es de 1,5; mientras Duffield et al. (1997) señalan 1,33 como margen superior. Toni et al. (2011) reportaron que, con valores mayores a 2,0 se observa efectos negativos en la producción de leche e incidencia de enfermedades. En nuestro estudio, el 83,2\% estuvo dentro de los valores normales $(1,0-1,5)$, con $7,4 \%$ por debajo de 1,0 , indicativo de posible acidosis ruminal, y el restante $9,27 \%$ excedió 1,5 y, lo cual se considera en riesgo de cetosis, quistes ováricos, renqueras y mastitis (Heuer et al. 1999). Asimismo, Toni et al. (2011) indican que vacas con estas características, en el período posparto, producen más leche pero tienen un desempeño reproductivo muy pobre. Además, Geishauser et al. (1998), Heuer et al. (1999) y Toni et al. (2011) han encontrado asociación entre altos valores de relación grasa/proteína en leche y el desplazamiento izquierdo de abomaso. Además, señalan, estos mismos investigadores, que vacas con una relación grasa/proteína muy alta en lactación temprana sufren descarte temprano y se puede observar un efecto negativo importante en el hato cuando el $10 \%$ o más presenta una relación mayor a 2,0 (Toni et al. 2011).

Respecto al MUN, se ha reportado valores objetivos o referenciales, de nitrógeno ureico que varían según diferentes autores; por ejemplo, McCormick et al. (2002) menciona valores normales entre 12,0 a 18,0 mg/dl; Kohn et al. (2002), por su parte, hacen referencia a valores entre 8,5 y $11,5 \mathrm{mg} / \mathrm{dl}$. Con respecto a estos valores, se puede notar que, a pesar de que la media de los animales del estudio se encuentra entre los valores referenciales, los valores máximos de la mayoría de las fincas se observan por fuera de estos; así, bajo el percentil 10 se observó valores por debajo de 12,10 mg/dl y, sobre el percentil 90, valores por encima de 20,4 mg/dl.

Godden et al. (2001) y Johnson \& Young (2003) reportaron pequeñas diferencias entre las lactancias, pero siempre con la mayor concentración de MUN en la primera y segunda. Altos valores de MUN, al primer parto, se puede atribuir al crecimiento del tejido magro y a una mayor utilización de aminoácidos, al tener como consecuencia una mayor formación de úrea en el hígado (Biswajit et al. 2011); sin embargo, en este estudio, no se observó valores estadísticamente diferentes entre los grupos.

Johnson \& Young (2003) observaron que el efecto de la fase de la lactación es uno de los más importantes sobre el MUN, con los valores más bajos en los primeros 30 días de lactancia. Otros estudios reportan disminución del MUN en los primeros meses de lactancia y un posterior 
aumento rápido durante los siguientes dos meses hasta llegar a una concentración máxima a los seis meses de lactancia, que posteriormente, desciende lentamente durante la lactancia tardía (Godden et al. 2001); situación muy similar a la presentada en esta investigación. Carlsson y colaboradores (1995) sugieren que los bajos valores de MUN en el primer mes de lactancia corresponden a la incapacidad de las vacas de digerir suficiente cantidad de comida al inicio de la lactación, lo cual resulta en una menor ingesta de proteínas. Por otra parte, Biswajit et al. (2011) proponen que estas diferencias entre los valores de MUN, se deben a cambios en la composición de la ración o programas de alimentación según cada etapa de lactación, demostrando así que factores no nutricionales tienen influencia en los valores de MUN.

En el estudio, no se encontró una diferencia estadísticamente significativa entre las concentraciones promedio de MUN para ambas razas, resultado que no concuerda con lo reportado en la literatura, pues diversos estudios encontraron que las Jersey mostraban valores más bajos de MUN al compararlas con Holstein (Johnson \& Young 2003; Arunvipas et al. 2004; Wattiaux et al. 2005).

En este estudio se observó una diferencia significativa entre el muestreo realizado en la época seca versus la lluviosa, en contraste con las altas concentraciones de MUN reportadas por Wattiaux et al. (2005) y Biswajit et al. (2011) meses de verano. Desafortunadamente, en este estudio, no se analizaron en este estudio, no se controló la ingesta de agua, ni se estudió el cambio climático en ese momento; por consiguiente, no se podría establecer una relación estricta entre ambas variable 0 , al menos, explicarla basada en manejo nutricional de los animales.

\section{Conclusiones}

Los valores degrasa, proteína y nitrógeno ureico, descritos en esteestudio, tienen comportamientos muy similares a los reportados en otros países, lo cual sugiere que se pueden utilizar como referencia en el momento de analizar los componentes de la leche en animales de hatos ubicados en zonas climáticas similares, con manejo y características raciales parecidos. En este aspecto, el control lechero mensual, en que se determinen los componentes de la leche, de forma individual de las vacas, resulta ser una práctica de amplia utilidad, no solo para el manejo individual, sino de la salud general del hato, tal como se realiza en países con larga tradición lechera. Las variaciones existentes en los porcentajes de grasa, proteína, relación grasa/proteína y nitrógeno ureico, según la etapa productiva del animal, la raza y la época de muestreo, indican que deben ser tomadas en cuenta en el momento de analizar el desempeño productivo, reproductivo y la salud de los animales, así como la relación con la dieta que se suministra.

\section{Referencias Bibliográficas}

Arunvipas, P., VanLeeuwen, J.A., Dohoo, I.R. \& Keefe, G.P. 2004. Bulk tank milk urea nitrogen: Seasonal patterns and relationship to individual cow milk urea nitrogen values. Can. J. of Vet. Res. 68 (3): 169-174. 
Biswajit, R., Brahma, B., Ghosh, S., Pankaj, P.K. \& Mandal, G. 2011. Evaluation of milk urea concentration as useful indicator for dairy herd management: A review. Asian. J. Anim. Vet. Adv. 6: 1-19. DOI:10.3923/ajava.2011.1.19

Brand, A., Noordhuizen, J.P.T.M. \& Schukken, Y.H. 1996. Herd Health and Production Managment in Dairy Practice. Wageningen Pers. Holanda. 466 p.

Cao, Z., Huang, W., Wang, T., Wang, Y., Wen, W., Ma, M. \& Li, S. 2010. Effects of parity, days in milk, milk production and milk components on milk urea nitrogen in Chinese Holstein. Journal of Animal and Veterinary Advances, 9 (4): 688-695. DOl:10.3923/javaa.2010.688.695

Carlsson, J., Bergsrtom, J. \& Pehrson, B. 1995. Variations with breed, age, season, yield, stage of lactation and herd in the concentration of urea in bulk milk and individual cow's milk. Acta. Vet. Scand. 36: 245-254.

Duffield, T.F., Kelton, D.F., Leslie, K.E., Lissemore. K.D \& Lumsden, J.H. 1997. Use of test day milk fat and milk protein to detect subclinical ketosis in dairy cattle in Ontario. Can. Vet. J. 38: 713-718.

Eicher, R. 2004. Memorias del Congreso Mundial de Buiatría. [en línea]. 11-16 de julio 2004. Quebéc Canadá. http://www.ivis.org/proceedings/wbc/wbc2004/WBC2004-Eichersimple.pdf (Consultado: 1 mar. 2012).

Geishauser, T.D., Leslie, K.E., Duffield, T.F.B \& Edge, V.L. 1998. An evaluation of protein/fat ratio in first $\mathrm{DHI}$ test milk for prediction of subsequent displaced abomasum in dairy cows. Can. J. Vet. Res. 62: 144-147.

Godden, S.M., Lissemore, K.D., Kelton, D.F., Leslie, K.E., Walton, J.S. \& Lumsden, J.H. 2001. Relationships between milk urea concentrations and nutrition management, production and economic variables. J. Dairy Sci. 84: 1128-1139. DOI: 10.3168/jds.S0022-0302(01)74573-0

González, A. \& Vázquez, 0. 2000. Análisis de urea en leche como indicador del balance nutritivo de la alimentación de las vacas. [en línea]. Centro de Investigaciones Agrarias Mabegondo. España. http://www.laboratoriollamas.com.ar/articulos/ bovinos/Urea\%20en\%20Leche\%20como\%20indicador\%20de\%20nutricion.pdf. (Consultado: 8 febrero de 2012).

Heinrichs, J., Jones, C. \& Bailey, K. 2005. Milk components: Understanding the causes and importance of milk fat and protein variation in your dairy herd. DAS 05-97. The Pennsylvania State Univ., University Park.

Heuer, C., Y. H. Schukken, and P. Dobbelaar. 1999. Postpartum body condition score and results from the first test day milk as predictors of disease, fertility, yield, and culling in commercial dairy herds. J. Dairy Sci. 82 (2): 295-304. DOI: 10.3168/jds.S0022-0302(99)75236-7

Hwang, S.Y., Lee, M. \& Chiou, P.W. 2000. Monitoring nutritional status of dairy cows in Taiwan using milk protein and milk urea nitrogen. Asian-Aus. J. Anim. Sci. Vol: 13 (12): 16671673. DOI: http://dx.doi.org/10.5713/ajas.2000.1667

Johnson, R.G., Young, A.J. 2003. The association between milk urea nitrogen and DHI production variables in western commercial dairy herds. 2003. J. Dairy Sci. 86(9):30083015. DOI: 10.3168/jds.S0022-0302(03)73899-5 
Jonker, J.S. \& Kohn, R.A. 2001. Using milk urea nitrogen to evaluate diet formulation and environmental impact on dairy farms. The Sci. World J. 1 (S2): 852-859.

Kohn, R.A., Kalscheur, K.F. \& Russek-Cohen, E. 2002. Evaluation of models to estimate urinary nitrogen and expected milk urea nitrogen. J. Dairy Sci. 85(1): 227-233. DOI: 10.3168/ jds.S0022-0302(02)74071-X

Kuterovac, K., Balas, S., Gantner, V., Jovanovac, S., \& Dakic, A. 2005. Evaluation of nutritional status of dairy cows based on analysis results. Ital. J. Anim. Sci. 4 (S3): 33-35. DOI: 10.4081/ijas.2005.3s.33

McCormick, M.E., Chapa, A.M., Fernández, J.M. \& Beatty, J.F. 2002. Milk urea nitrogen evaluation in Louisiana dairy herds. [en línea]. http://www.lsuagcenter.com/nr/rdonlyres/b197egfb2759-431d-867bcda77a10629b/9190/munla.pdf (Consultado: 15 mar. 2012).

Niles, D. 2010. Identifying rumen acidosis and related problems using fat/protein ratios. Canwest DHI. [en línea]. http://www.canwestdhi.com/pdf_files/february\%20 2010\%20bc\%20holstein.pdf. (Consultado: 17 mar. 2012).

Noordhuizen, J.P. \& Buurman, J. 1984. VAMPP: a veterinary automated management and production control programme for dairy farms (the application of MUMPS for data processing). Vet O. 6(2): 66-72.

Noordhuizen, J.P.T.M. 2002. Memorias del XXII Congreso Internacional de Buiatría. Agosto 18-23. Hannover Alemania.

Oetzel, G.R. 2007. Preconference Seminar $7^{\text {a: }}$ Dairy Problem Investigation Strategies: Lameness, cow comfort, and ruminal acidosis. [en línea]. American Association of Bovine Practitioners. Canadá. http://www.vetmed.wisc.edu/dms/fapm/fapmtools/2nutr/ sara1aabp.pdf (Consultado: 27 feb. 2012).

Padilla, R. 2010. Perfiles metabólicos en bovinos especializados en producción de leche de la raza Holstein, en la zona del Volcán Poás. Tesis de Licenciatura, Universidad Nacional, Heredia, Costa Rica.

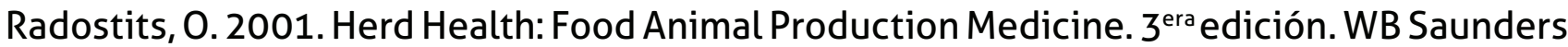
Company. EE.UU. 890 p.

Robinson, P. 2000. Manipulating milk protein percentage and production in lactating dairy cows. Adv Dairy Technol. [en línea]. 12:269-278. http://www.wcds.ca/proc/2000/ Manuscripts/Chapter\%2022\%20-\%20Robinson.pdf. (Consultado: 27 feb. 2012).

Romero, J].; Estrada, S. \& Pérez, E. 2000. Uso del sistema de información VAMPP en investigaciones a gran escala. XVII Congreso Panamericano de Ciencias Veterinarias, Ciudad de Panamá, Panamá. p. 101.

Toni, F., Vincenti, L., Grigoletto, L., Ricci, A. \& Schukken, Y.H. 2011. Early lactation ratio of fat and protein percentage in milk is associated with health, milk production and survival. J. Dairy Sci. 94(4):1772-1783. DOI: 10.3168/jds.2010-3389.

Van Ranst, B., Caluwaerts, T., Van der Beek, H.J. \& Opsomer, G. 2008. Memorias del XXV Congreso Mundial de Buiatría. Jul 6-11. Budapest, Hungría.

Wattiaux, M.A., Nordheim, E.V. \& Crump, P. 2005. Statistical evaluation of factors and interactions affecting dairy herd improvementmilkureanitrogen in commercialmidwest dairy herds. J.Dairy Sci. 88: 3020-3035. DOI:10.3168/jds.S0022-0302(05)72982-9 